\title{
Central cholinergic blockade by scopolamine and habituation, classical conditioning, and latent inhibition of the rabbit's nictitating membrane response
}

\author{
JOHN W. MOORE, NANCY A. GOODELL, and PAUL R. SOLOMON \\ University of Massachusetts at Amherst, Amherst, Massachusetts 01002
}

\begin{abstract}
Rabbits injected with scopolamine hydrobromide $(1.5 \mathrm{mg} / \mathrm{kg})$ were contrasted with control animals injected with scopolamine methylbromide or saline in terms of habituation of the unconditioned nictitating membrane response (NMR), classical defensive conditioning, and latent inhibition using auditory and visual conditioned stimuli. Scopolamine hydrobromide disrupted classical conditioning in comparison with drug controls, but had no adverse effects on habituation of the unconditioned reflex or on latent inhibition. The drug also raised thresholds of the auditory (but not visual) CS for eliciting the conditioned NMR. Results were discussed in terms of presumed cholinergiclimbic system involvement in Pavlovian conditioning and inhibition.
\end{abstract}

Central cholinergic mechanisms have been implicated in animal learning and conditioning, particularly those processes involving response inhibition (cf. Carlton, 1969; Deutsch, 1971). The present investigation sought information on the role of central cholinergic systems on habituation, classical conditioning, and latent inhibition of the rabbit's nictitating membrane response (NMR).

\section{EXPERIMENT I}

Previous research (Downs, Cardozo, Schneiderman, Yehle, VanDercar, \& Zwilling, 1972) has shown that central cholinergic blockade by atropine sulfate retards classical conditioning of the rabbit's NMR to a tone conditioned stimulus (CS) based on an electric shock unconditioned stimulus (UCS) to the eye. Retarded acquisition in this case could come about either because the drug somehow disrupts the formation of the connection between the CS and the conditioned response (CR) or because the drug alters the unconditioned reflex (UCR) upon which conditioning is based. Downs et al. (1972) reported that UCR amplitude was not noticeably altered by the drug. While this observation suggests that central cholinergic blockade does not affect the UCR, the possibility remains that such disruption as may exist is subtle and obscured by an eliciting stimulus as intense as that employed in their experiment $(3 \mathrm{~mA}$ ac and of $.5 \mathrm{sec}$ duration). Experiment I was designed to uncover any spurious effects of scopolamine on

This research was supported by NSF Grant BMS 75-02270. Requests for reprints should be addressed to John W. Moore, Department of Psychology, Middlesex House, University of Massachusetts, Amherst, Massachusetts 01002. P. R. Solomon is presently at Williams College, Williamstown, Massachusetts. the unconditioned NMR by employing a relatively weak UCS presented repeatedly over a series of habituation trials.

\section{Method}

Animals. The animals were 18 experimentally naive white New Zealand rabbits weighing approximately $3 \mathrm{~kg}$. They were individually caged with ad lib. access to feed and water.

Apparatus and Procedures. The apparatus and general procedures for restraining, running, and recording rabbits in the NMR preparation are described elsewhere (e.g., Moore, Marchant, \& Norman, 1973). Animals were prepared for recording the NMR and accustomed to restraint and experimental chambers on Day 1. Habituation testing began on Day 2 and was repeated on Days 3-5. The habituating stimulus was an electric shock $(.25 \mathrm{~mA}$ ac and of $50 \mathrm{msec}$ duration) delivered via 9-mm wound-clip electrodes attached to the infraorbital region, one immediately inferior and the other posterior to the right (recorded) eye. The eye shock was presented 120 times per session at a constant rate of 1 every $30 \mathrm{sec}$. The shock was increased to $2 \mathrm{~mA}$ on Trials 41 , 61,81 , and 101 in an attempt to dishabituate the NMR.

Three groups of eight rabbits received subcutaneous injections of scopolamine hydrobromide at a dosage of $1.5 \mathrm{mg} / \mathrm{kg}$ dissolved in isotonic saline $(2 \mathrm{mg} / \mathrm{ml})$, scopolamine methylbromide at the same dosage and concentration, or saline alone. The injections were given each day $30 \mathrm{~min}$ before testing. Scopolamine methylbromide presumably does not cross the blood brain barrier and therefore provides a means of distinguishing between central vs. peripheral effects of the drug.

\section{Results and Discussion}

In order to determine whether scopolamine affected the amplitude of the NMR and its rate of habituation, the first 40 trials to the $.25-\mathrm{mA}$ shock on each day were broken down into blocks of 10 . The mean amplitude of responses for each block was computed in terms of millimeters of deflection of the oscillograph recording pen. Analysis of variance of these mean amplitude scores was carried out in a 3 by 4 by 4 factorial layout with drug treatment as a "between" 
factor and days and blocks as crossed "within" factors. The only statistically significant source of variance was the blocks main effect with mean amplitudes of $10.1,8.9,8.4$, and $7.8 \mathrm{~mm}$ on Blocks $1-4$, respectively, $F=10.88, \mathrm{df}=3 / 45$, $\mathrm{p}<.005$. The drugs main effect yielded $\mathrm{F}<1$, and none of the other sources of variance, most notably those involving the interaction of drug treatment with days and/or blocks, approached significance (Fs $<2$ ).

Amplitude scores for Trials 42-60, 62-80, 82-100, and 102-120 were averaged for each animal, yielding four scores summarizing the remaining trials to the .25 -mA eye shock for each day of testing. Analysis of variance in a 3 by 4 by 4 (Drug by Days by Blocks) factorial layout failed to reveal any significant sources of variance $(\mathrm{Fs}<2)$.

Dishabituation by the $2-\mathrm{mA}$ eye shock presented each day on Trials $41,61,81$, and 101 was assessed in terms of the difference in amplitude between the trial following a strong shock and the trial preceding a strong back. On the average, amplitude of the NMR to the $.25-\mathrm{mA}$ shock increased only $.6 \mathrm{~mm}$ following the dishabituating stimulus. This slight increase was not reliable, and analysis of variance of difference scores in the 3 by 4 by 4 factorial layout failed to reveal any significant sources of variance (Fs $<2)$.

In summary, significant within-session habituation of the NMR to a .25-mA eye shock was observed, but the amplitude of the NMR or its rate of habituation was unaltered by scopolamine. Dishabituation by a stronger eye shock was unreliable and unaffected by the drug. These observations are consistent with the Downs et al. (1972) study in suggesting that UCR mechanisms of the classically conditioned NMR in rabbits are unaffected by central cholinergic blockade.

\section{EXPERIMENT II}

This experiment was designed to determine whether scopolamine retards classical conditioning of the rabbit's NMR to a tone CS based on infraorbital electric shock. Scopolamine methylbromide was included as a control in order to determine whether any observed retardation of conditioning could be accounted for by peripheral action of the drug.

A second purpose of Experiment II was to determine whether scopolamine affected latent inhibition, i.e., the phenomenon observed in a variety of animal learning and conditioning situations whereby exposure to the conditioned stimulus or cue prior to conditioning retards acquisition of the CR (cf. Lubow, 1973). Latent inhibition in the rabbit NMR preparation is thought to involve "tuning out" the CS through a habituation-like process, and this diminution of the salience of the CS is presumably responsible for retardation of conditioning (Reiss \& Wagner, 1972; Solomon, Lohr, \& Moore, 1974).

\section{Method}

Animals. The animals were 30 experimentally naive white New Zealand rabbits weighing approximately $3 \mathrm{~kg}$. They were individually caged with ad lib. access to feed and water.

Apparatus and Procedures. On the day following adaptation to restraint, etc., each animal received a subcutaneous injection of scopolamine hydrobromide $(1.5 \mathrm{mg} / \mathrm{kg}$ dissolved in isotonic saline at a concentration of $2 \mathrm{mg} / \mathrm{ml}$ ), scopolamine methylbromide at the same dosage and concentration, or saline alone. There were 10 rabbits in each drug condition, and injection preceded each day's session by $30 \mathrm{~min}$.

In order to establish the CS as a latent inhibitor of classical conditioning, half the arimals in each drug condition received 100 nonreinforced presentations of the CS at a constant rate of 1 every $30 \mathrm{sec}$. The remaining five animals under each drug treatment did not experience preexposure to the CS prior to conditioning. Instead, these animals received the drug or saline and, 30 min later, were placed in the conditioning chambers under restraint for $50 \mathrm{~min}$. After 4.5 of these "sit" sessions, conditioning trials ensued for up to 9.5 sessions.

The CS was a $1,200-\mathrm{Hz}$ pure tone of $75 \mathrm{~dB}$ SPL and of $450 \mathrm{msec}$ duration. The reinforcer or UCS was an eye shock of $2 \mathrm{~mA}$ ac and $50 \mathrm{msec}$ duration. The two stimuli were terminated together so that the CS-UCS interval was $400 \mathrm{msec}$. Conditioned responses were defined as oscillographic pen deflections of at least $1 \mathrm{~mm}$ (corresponding to an NMR of less than $1 \mathrm{~mm}$ ) within the CS-UCS interval.

\section{Results and Discussion}

The rate of acquisition of the conditioned NMR was summarized by a single datum for each animal, the number of trials to achieve five consecutive CRs. The mean trials to criterion for each group are given in Table 1. Analysis of variance was carried out in a 3 by 2 factorial layout with drug treatment crossed with number of CS preexposures. The only statistically significant source of variance was drug treatment, $F=6.07, \mathrm{df}=2 / 24, \mathrm{p}<.01$. Planned pairwise comparisons among the three drug treatments, pooled across CS-preexposure conditions, revealed that scopolamine hydrobromide retarded conditioning significantly more than scopolamine methylbromide, $\mathrm{t}=2.27, \mathrm{df}=24, \mathrm{p}<.05$, and also significantly more than saline alone, $t=3.50$, $\mathrm{df}=24, \quad \mathrm{p}<.05$. Scopolamine methylbromide animals were not significantly slower to condition than animals that received saline alone.

Table 1 shows a consistent trend in the generally slower rate of conditioning following $450 \mathrm{CS}$ preexposures than following the "sit" ( 0 preexposure $)$

Table 1

Mean Trial of First of Five Consecutive CRs for Each Group of Experiment II

\begin{tabular}{cccc}
\hline & \multicolumn{3}{c}{ Drug Treatment } \\
\cline { 2 - 4 } $\begin{array}{c}\text { Number of } \\
\text { CS Preexposures }\end{array}$ & $\begin{array}{c}\text { Scopolamine } \\
\text { Hydrobromide }\end{array}$ & $\begin{array}{c}\text { Scopolamine } \\
\text { Methylbiomide }\end{array}$ & Saline \\
\hline 450 & 539.6 & 294.4 & 175.4 \\
0 & 421.0 & 223.8 & 126.8 \\
\hline
\end{tabular}


treatment. This held for each drug treatment and is clearly suggestive of a latent inhibition effect. However, the main effect of the CS-preexposure condition was not a significant source of variance, $F=$ 1.02 , df $=1 / 24$, nor was the interaction of the two factors in the design $(F<1)$.

In summary, scopolamine hydrobromide significantly retarded acquisition of the conditioned NMR to a tone CS, and contrasts with scopolamine methylbromide indicated that this retardation was primarily due to the central rather than peripheral effects of the drug. The question of whether central cholinergic blockade disrupts the phenomenon of latent inhibition remains unanswered. A comparison between CS preexposed animals and "sit" controls injected with scopolamine hydrobromide did not approach statistical significance, but acceptance of the null hypothesis may not be warranted because of the small number of animals in each group.

\section{EXPERIMENT III}

The purpose of this experiment was to determine whether scopolamine hydrobromide altered the threshold of the tonal CS employed in Experiment II. Altered thresholds for eliciting the CR could conceivably account for the main findings of Experiment II.

\section{Method}

Animals. The animals were those employed in Exper1ment II.

Procedures. Following 2 days of experimental extinction of the nonreinforced CS (100 trials/day), the tone CS was presented 100 times (once every $30 \mathrm{sec}$ ) at varying intensity in order to determine the threshold for eliciting the CR. (Extinction was carried out under the same drug condition in effect during acquisition. There were no statistically significant effects of drug treatment on resistance to extinction.) All threshold test trials were reinforced, and animals received the same drug treatment given in Experiment II prior to the threshold test. The first five trials were at $75 \mathrm{~dB} \mathrm{SPL}$, the intensity employed during conditioning. The $C R$ was reinstated to full strength within this initial series. Tone intensity was then decreased in $5-\mathrm{dB}$ steps until the CR disappeared. Five trials were given at each intensity. When the block of five trials was reached in which no CRs occurred, the intensity was increased in 5-dB steps to the initial intensity of $75 \mathrm{~dB}$. Each intensity was presented five times in succession during the ascending series. Auditory threshold of the CS was determined as the first block of 10 trials (descending plus ascending) containing fewer than five CRs.

\section{Results and Discussion}

The mean thresholds of the tonal CS for eliciting the conditioned NMR for each group of animals are given in Table 2.

Analysis of variance of CS thresholds indicated a significant main effect due to drug treatment, $\mathrm{F}=12.00, \mathrm{df}=2 / 24, \mathrm{p}<.005$. Planned pairwise contrasts indicated that scopolamine hydrobromide significantly elevated thresholds above those obtained
Table 2

Mean Threshold Intensity of the Tone CS (dB SPL) Employed in Experiment III

\begin{tabular}{cccc}
\hline & \multicolumn{3}{c}{ Drug Treatment } \\
\cline { 2 - 4 } $\begin{array}{c}\text { Number of } \\
\text { CS Preexposures }\end{array}$ & $\begin{array}{c}\text { Scopolamine } \\
\text { Hydrobromide }\end{array}$ & $\begin{array}{c}\text { Scopolamine } \\
\text { Methylbromide }\end{array}$ & Saline \\
\hline 450 & 67 & 56 & 47 \\
0 & 58 & 52 & 48 \\
\hline
\end{tabular}

under scopolamine methylbromide, $\mathrm{t}=3.59$, $\mathrm{df}=$ $24, \mathrm{p}<.01$, and saline alone, $\mathrm{t}=5.12$, $\mathrm{df}=24$, $\mathrm{p}<.01$. Thresholds for scopolamine methylbromide did not differ significantly from those observed among saline controls, $\mathrm{t}=1.54, \mathrm{df}=24$.

Table 2 suggests that CS preexposure contributed to the elevation of CS thresholds observed under scopolamine hydrobromide. CS preexposure produced a smaller elevation of CS thresholds in animals injected with scopolamine methylbromide but had no effect on CS thresholds of saline animals. However, analysis of variance failed to confirm the reliability of this apparent interaction between drug treatment and CS preexposure suggested by this pattern of results, $F=2.60, \mathrm{df}=2 / 24, \mathrm{p}<.10$.

There are several points in the auditory system which are potentially vulnerable to cholinergic blockade. For example, the dorsal tegmental pathway of Shute and Lewis (1967) contains cholinergic elements which interact directly with the inferior colliculus and indirectly with the medial geniculate nuclei. The threshold shifts observed in Experiment III may involve disruption of interactions between auditory relays and cholinergic elements in the reticular core.

\section{EXPERIMENT IV}

Elevated threshold by the tonal CS by scopolamine hydrobromide could clearly contribute to the retardation of conditioning under the drug described in Experiment II. In addition, the finding that CS preexposure plus the drug yielded the highest average CS threshold could account for the apparent (though statistically nonsignificant) latent inhibition effect observed in the scopolamine hydrobromide groups in Experiment II. Questions concerning the precise role CS threshold left unresolved the basic issue of cholinergic involvement in conditioning and latent inhibition. Experiment IV attempted to avoid these complexities by employing a light CS instead of a tone in the hope that any alterations of CS thresholds by the drug would be less pronounced in the visual modality than in the auditory modality.

\section{Method}

Animals. The animals were 16 experimentally. naive rabbits like those employed in Experiments I-III. 


\begin{abstract}
Apparatus and Procedures. Apparatus and general procedures were the same in the previous experiments, except that two 4.5 V incandescent panel lights (behind white diffusing plastic panels) served as the CS. Twelve animals were injected with scopolamine hydrobromide prior to each daily session. The animals were run in three replications of four rabbits each with two animals in each squad receiving $450 \mathrm{CS}$ preexposures and two serving as "sit" controls with no CS preexposures. All animals were subsequently conditioned to a criterion of at least five consecutive CRs. Following conditioning, the four animals in the first replication received one additional reinforced session under the drug to determine the threshold of the light CS. A rheostat with eight equally spaced settings was put in series with one panel light. The other light was disconnected. Threshold was determined by systematically decreasing then increasing the intensity of the light in five-trial blocks until determination of the rheostat setting yielded fewer than $50 \%$ CRs.

Four drug-control animals were included in the design: two injected with scopolamine methylbromide prior to each session and two injected with saline alone. One animal in each pair experienced $450 \mathrm{CS}$ preexposures and one served as a "sit" control. These drug-control animals were run together with the first squad of animals injected with scopolamine hydrobromide and also received the CS threshold test.
\end{abstract}

\section{Results and Discussion}

Pooling over number of CS preexposures, the 12 animals injected with scopolamine hydrobromide required an average of 511 trials to attain a criterion of five consecutive CRs. The four drug-control animals required only 82 trials, on the average, to reach this level of performance. This difference is significant by a Mann-Whitney test, $\mathrm{U}(12,4)=2$, $\mathrm{p}<.01$. In marked contrast with the adverse effects of the drug on conditioning observed in Experiment II, where a tone served as the CS, retarded conditioning to the light could not be attributed to elevated CS thresholds. Using an 8-point scale of rheostat settings, thresholds to the light CS for the eight animals tested ranged from 2 to 5 . The average setting for the four animals injected with scopolamine hydrobromide was 3 , exactly equal to that of the four drug-control animals.

The two drug-control animals receiving $450 \mathrm{CS}$ preexposures required 94 and 155 trials to reach the criterion of five consecutive CRs. The two drugcontrol "sit" ( 0 preexposure) animals required only 37 and 41 trials to reach criterion. These observations suggest that latent inhibition can be obtained with a light $\mathrm{CS}$ as well as a tone.

The primary concern, of course, was whether latent inhibition would appear in animals injected with scopolamine hydrobromide. The average trials to criterion for those drugged animals receiving 450 CS preexposures was 693 as compared with 328 for "sit" controls. Analysis of variance in a 2 by 3 factorial layout, with number of CS preexposures as one factor and replications as the other, indicated this difference to be significant, $F=8.40, d f=1 / 6$, $\mathrm{p}<.05$.

In summary, scopolamine hydrobromide disrupted conditioning to a light CS, but this disruption could not be attributed to effects of the drug on CS threshold, for none were observed. While drugged animals that never experienced the light CS prior to the onset of conditioning were slow to acquire the CR in comparison with drug controls, those experiencing $450 \mathrm{CS}$ preexposures were even slower. Thus, scopolamine hydrobromide did not eliminate the latent inhibition effect.

\section{GENERAL DISCUSSION}

This research implicates central cholinergic (muscarinic) synapses in classical conditioning of the rabbit's NMR based on electric shock to the infraorbital region of the eye. Systemic injection of scopolamine hydrobromide retarded acquisition of the CR to both an auditory and a visual CS. In the auditory case, retarded conditioning was accompanied by elevated thresholds of the CS for eliciting the CR. The drug did not appear to alter thresholds to the visual CS. Nor was there any apparent effect of the drug on the amplitude of the UCR or its rate of habituation to a weak shock.

This study is consistent with an earlier report (Downs, et al., 1972) in showing that central cholinergic blockade by a belladonna alkaloid interferes with acquisition but not the ultimate performance of a classically conditioned defensive eye reflex in rabbits. However, these studies provide few clues as to whether cholinergic blockade affects conditioning directly, by interrupting the flow of activity between the CS and CR along crucial synaptic linkages, or indirectly, either by altering tonic neuropharmacological relationships between cholinergic and other (presumably crucial) neurotransmitter systems or by acting on collateral structures which normally serve to regulate or guide activity along the path(s) linking the CS with the CR. The fact that drugged animals ultimately acquired a robust $C R$ may indicate development of tolerance to the drug, but this interpretation is mitigated by the finding that thresholds to the auditory CS were significantly altered despite several prior daily injections with the drug, within which time the $C R$ invariably emerged.

The more surprising result of the present research is evidence that latent inhibition survives cholinergic blockade with a dosage of scopoloamine sufficient to retard acquisition of the CR. This result is of interest because of the widely held assumption that central cholinergic systems have something to do with behavioral inhibition in general (e.g., Carlton, 1969) and Pavlovian internal inhibition in particular (e.g., Douglas, 1972). This premise is based on evidence that cholinergic blockade often mimics the effect of lesions to limbic system structures, such as the septo-hippocampus complex, which have 
been shown to play a role in one form of inhibition or another. Lewis and Shute's (1967) anatomical findings of extensive cholinergic pathways mediating limbic-midbrain interactions in rats are consistent with this hypothesis of a central cholinergic system anatomically located in the septo-hippocampus complex. Additional evidence comes from studies which have shown that intraseptal and intrahippocampal injections of atropine heightened locomotive activity in rats (Leaton \& Rech, 1972).

What role does the septo-hippocampus complex play in inhibition of the rabbit's conditioned NMR? Solomon and Moore (1975) have shown that bilateral dorsal hippocampectomy disrupts latent inhibition of a tonal CS and tends to flatten stimulus generalization gradients along the audio-frequency dimension. Lockhart and Moore (1975) found that rabbits with bilateral septal lesions gave significantly more "false positives" in differential conditioning between two tones than did normal rabbits. While these results are generally consistent with the rat literature (cf. Isaacson, 1974), the present research suggests that, whatever neuropharmacological systems are affected by septo-hippocampus damage to the detriment of Pavlovian inhibition in rabbits, the cholinergic elements may not be essential. This conclusion is strengthened by other (unpublished) research in our laboratory in which scopolamine hydrobromide was found to have no adverse affect whatever on either simple differential conditioning between a light $(\mathrm{CS}+)$ and tone $(\mathrm{CS}-)$ or conditioned inhibition training with a light as $\mathrm{CS}+$ and a light-tone compound as CS - .

\section{REFERENCES}

Carlton, P. L. Brain acetylcholine and inhibition. In J. Tapp (Ed.), Reinforcement and behavior. New York: Academic Press, 1969.
Deutsch, J. A. The cholinergic synapse and the site of memory. Science, 1971, 174, 788-794.

Douglas, R. J. Pavlovian conditioning and the brain. In R. A. Boakes \& M. S. Halliday (Eds.), Inhibition and learning. New York: Academic Press, 1972.

Downs, D., Cardozo, C., Schneiderman, N., Yehle, A. L., VANDERCAR, D. H., \& Zwilling, G. Central effects of atropine upon aversive classical conditioning in rabbits. Psychopharmacologia, 1972, 23, 319-333.

IsAaCson, R. L. The limbic system. New York: Plenum Press, 1974.

LEATON, R. N., \& RECH, R. H. Locomotor activity increases produced by intrahippocampal and intraseptal atropine in rats. Physiology and Behavior, 1972, 8, 539-541.

Lewis, P. R., \& Shute, C. C. D. The cholinergic limbic system: Projections to the hippocampal formation, medial cortex, nuclei of the ascending cholinergic reticular system, and the subfornical organ and supraoptic crest. Brain, 1967, 90, 521-540.

LOCKHART, M., \& MOORE, J. W. Classical differential and operant conditioning in rabbits (Oryctolagus cuniculus) with septal lesions. Journal of Comparative and Physiological Psychology, 1975, 88, 147-154.

Luвow, R. E. Latent inhibition. Psychological Bulletin, 1973, 79, 398-407.

Moore, J. W., Marchant, H. G., III, Norman, J. B., \& Kwaterski, S. E. Electrical brain stimulation as a Pavlovian conditioned inhibitor. Physiology and Behavior, 1973, 10. 581-587.

ReISS, S., \& WAGNER, A. R. CS habituation produces a "latent inhibition effect" but no active conditioned inhibition. Learning and Motivation, 1972, 3, 237-245.

Shute, C. C. D., \& Lewis, P. R. The ascending cholinergic reticular system: Neocortical, olfactory and subcortical projections. Brain, 1967, 90, 497-520.

Solomon, P. R., LoHr, A. C., \& Moore, J. W. Latent inhibition of the rabbit's nictitating membrane response: Summation tests for active inhibition as a function of number of CS preexposures. Bulletin of the Psychonomic Society, 1974, 6, 557-559.

Solomon, P. R., \& Moore, J. W. Latent inhibition and stimulus generalization of the classically conditioned nictating membrane response in rabbits (Oryctolagus cuniculus) following dorsal hippocampal ablation. Journal of Comparative and Physiological Psychology, 1975, 89, 1192-1203.

(Received for publication January 12, 1976; revision accepted May 5, 1976.) 